\title{
Detection of tick-borne infection in Morgellons disease patients by serological and molecular techniques
}

This article was published in the following Dove Press journal: Clinical, Cosmetic and Investigational Dermatology

\author{
Marianne J Middelveen' \\ Iris Du Cruz ${ }^{2}$ \\ Melissa C Fesler ${ }^{3}$ \\ Raphael B Stricker ${ }^{3}$ \\ Jyotsna S Shah ${ }^{2}$
}

'Atkins Veterinary Services, Calgary, $A B$, Canada; ${ }^{2} I G e n e X$ Laboratories, Palo Alto, CA, USA; ${ }^{3}$ Union Square Medical Associates, San Francisco, CA, USA

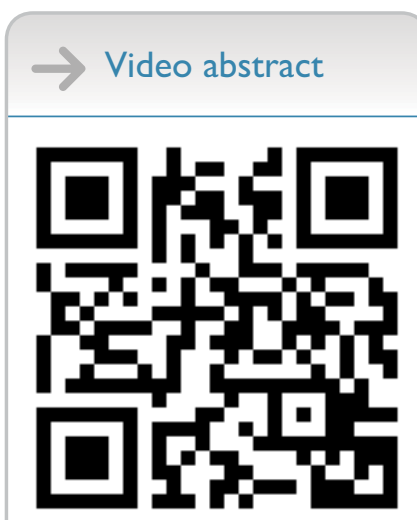

Point your SmartPhone at the code above. If you have a QR code reader the video abstract will appear. Or use: http://youtu.be/_VPHrvnWJRO
Correspondence: Raphael B Stricker Union Square Medical Associates, 450 Sutter Street, Suite 1504, San Francisco, CA 94108, USA

Email rstricker@usmamed.com
Background: Morgellons disease (MD) is a skin condition associated with Lyme disease (LD) and tick-borne illness. Patients with this skin disorder experience ulcerative lesions that contain multicolored filamentous collagen and keratin inclusions. Infection with various species of Borrelia and other tick-borne pathogens has been detected in tissue and body fluid specimens from MD patients. We sought to explore this association further in a cohort of MD patients.

Patients and methods: Sera from 30 patients with MD were tested for antibody reactivity to antigens from the Borrelia burgdorferi $(\mathrm{Bb})$ group and the relapsing fever Borrelia (RFB) group of spirochetes. Tissue and/or body fluid specimens from these patients were also tested for the presence of $\mathrm{Bb}$ and RFB infection using PCR technology. In addition, tissue and body fluid specimens were tested for the presence of Bartonella henselae using PCR, and formalinfixed skin sections from a subset of patients were tested using fluorescent in situ hybridization (FISH) with $B$. henselae-specific DNA probes.

Results: Seroreactivity to $\mathrm{Bb}$, RFB or both was detected in $63 \%$ of the cohort, while positive PCR testing for Bb, RFB or both was detected in 53\% of the cohort. Overall, $90 \%$ of patients tested positive for exposure and/or infection with Borrelia spirochetes. B. henselae infection was detected by PCR in skin sections or body fluids from $20 \%$ of the subjects, and $B$. henselae FISH testing was positive in $30 \%$ of the dermatological specimens submitted for study.

Conclusion: The study demonstrates an association between MD and positive tests for both $\mathrm{Bb}$ and RFB spirochetes. In conjunction with previous studies, our study provides corroborative evidence linking MD to Borrelia infection and tick-borne illness.

Keywords: Lyme disease, Borrelia burgdorferi, Morgellons disease, relapsing fever Borrelia, Bartonella, tick-borne disease

\section{Introduction}

Morgellons disease (MD) is a dermatological condition characterized by spontaneously occurring lesions that contain filamentous inclusions and/or projections. ${ }^{1,2}$ The presence of unusual filaments is the key diagnostic feature of this dermopathy. These cutaneous filaments are firmly attached, lying under, embedded in, or projecting from skin, and can be white, black or vibrant hues of other colors. ${ }^{1-4}$

Many physicians maintain that MD is synonymous with delusions of parasitosis (DOP), that it is purely psychogenic in origin and that the filaments are implanted textile fibers. ${ }^{5,6}$ In contrast, detailed scientific studies demonstrate that the disorder is associated with Lyme disease (LD) and other tick-borne illnesses and that the fibers are hair-like collagen and keratin filamentous growths produced by skin cells in the 
deeper layers of the epidermis, the upper layers of the dermis and the root sheath of hair follicles..$^{2-4,7,8}$ The coloration of blue fibers is due to melanin pigmentation, which is a finding that provides further proof that the fibers are not textile in origin. $3,4,7,8$

MD is not exclusively a skin disorder. It can be accompanied by Lyme-like symptoms such as fatigue, joint inflammation, cardiac manifestations and neuropathy, which suggest a spirochetal relationship. ${ }^{1-4,9-12}$ Results from two independent cohort studies established that LD was present in almost all patients with this disorder. A 2010 study reported that $98 \%$ of its 122 subjects either tested serologically positive for LD or were clinically diagnosed with LD. ${ }^{1}$ Similar results were reported in a 2018 study in which $100 \%$ of a cohort of $60 \mathrm{MD}$ patients tested positive for LD. ${ }^{13}$ Two independent studies, one in Australian patients and one in North American patients, reported that MD occurs in a subset of approximately $6 \%$ of LD patients. ${ }^{13,14}$ This evidence suggests that MD may be a physiological reaction to the presence of Borrelia spirochetes and coinfecting pathogens in genetically predisposed LD patients. ${ }^{3,4}$

Positive serology and/or molecular testing for Borrelia burgdorferi $(\mathrm{Bb})$ and relapsing fever Borrelia (RFB) has been reported in $\mathrm{MD}$ patients, and positive tests for coinfecting tick-borne pathogens (Babesia spp., Bartonella, Rickettsia, Ehrlichia and Anaplasma) have also been described in patients with this dermopathy. ${ }^{3,411-13,15}$ Both arthropodvectored (Bartonella spp.) and other non-arthropod-vectored, human-associated pathogens (Treponema denticola and Helicobacter pylori) have been detected in skin specimens from MD patients. ${ }^{3,4}$ These pathogens may play an etiological role in MD evolution or may be exacerbating factors that worsen the condition.

Positive testing for Borrelia and other pathogens in MD patients has only recently been described, and therefore evidence of an infectious etiology is controversial. We sought to undertake a confirmatory study using both serological and PCR methods to demonstrate Borrelia infection in 30 randomly selected $\mathrm{MD}$ patients who met the key diagnostic criterion of MD. We also performed molecular testing for Bartonella henselae to ascertain the prevalence of this infection in MD patients.

\section{Patients and methods}

\section{Patients and specimen collection}

Adult participants from across North America either accessed the study via the Charles E. Holman Morgellons Disease Foundation or contacted the researchers independently.
Informed consent for specimen collection and study participation was obtained from each patient, and the identities of participants were kept strictly confidential. The study protocol was approved by the Western Institutional Review Board (WIRB), Puyallup, WA, USA. Additional written consent to publish data resulting from this study was obtained for each patient. The study was conducted in accordance with the Declaration of Helsinki.

Participants were included in the chronological order in which they volunteered. All volunteers were included providing they met the diagnostic criterion for MD: embedded or projecting white, black or colored cutaneous filaments documented by a healthcare professional. Prior testing for LD or other tick-borne illnesses was not required nor was that information provided to the researchers. Patient samples without demographic information were sent to the laboratory conducting the testing, and this information was only added to the data and analyzed after laboratory testing had been concluded. Participants who had lesions containing thickened callus material were invited to collect and submit skin specimens for further evaluation using histological sectioning and special staining for Bartonella spp.

\section{Laboratory testing}

All experimental tests were conducted at IGeneX Laboratory (Palo Alto, CA, USA), which is a high-complexity testing laboratory with Clinical Laboratory Improvement Amendments (CLIA) certification.

\section{Borrelia Western blot (WB) testing}

The WB assays were performed as described previously to detect IgM and IgG antibodies reactive to $\mathrm{Bb}$ and RFB. ${ }^{16,17}$ Nitrocellulose strips for the $\mathrm{Bb}$ WB were prepared from whole cell lysates of a mixture of the Bbss strains B31 and 297, as previously described. ${ }^{16}$ Nitrocellulose strips for the RFB WB were prepared from whole cell lysates of two RFB species, Borrelia hermsii and Borrelia turcica, that crossreact with RFB species known to infect human beings. ${ }^{17}$ Thus, the RFB WB assay used in this study detected antibodies reactive with RFB but did not differentiate this group at the species level.

The $\mathrm{Bb}$ and RFB strips were reacted with test sera from the MD patients, positive control sera from patients with confirmed LD and RFB and negative control sera from uninfected people. Each strip was labeled and soaked in 1 $\mathrm{mL}$ of diluent (100 mM Tris, $0.9 \% \mathrm{NaCl}, 0.1 \%$ Tween $20 \%$ and $1 \%$ nonfat dry milk) for 5 minutes in a trough; then, $10 \mu \mathrm{L}$ aliquots of each test or control serum were added to 
a separate strip in troughs. The strips were then incubated at ambient temperature for 1 hour, followed by three washes with wash buffer (KPL, Gaithersburg, MD, USA) at ambient temperature. The remaining final wash solution was aspirated, after which the strips were incubated for 1 hour with alkaline phosphate-conjugated goat antihuman IgG and $\operatorname{IgM}(\mathrm{KPL})$ to detect $\operatorname{IgG}$ and $\operatorname{IgM}$, respectively, at 1:10,000 dilution for IgG and 1:6,000 dilution for IgM, then they were washed three times. The bands were then visualized by reaction with 5-bromo-4-chloro-3-indolylphosphatenitro-blue tetrazolium (BCIP/NBT; KPL). The enzymatic reactions were concluded by washing with distilled water at the point in time when a calibration control produced a visible band at $39 \mathrm{kDa}$. The calibration control consisted of an alkaline phosphatase-conjugated rabbit antibody to the $39 / 93 \mathrm{kDa}$ Bbsl antigens (Strategic Biosciences, Stow, MA, USA) diluted in human serum, as previously described. ${ }^{16}$ Bands displaying a lower intensity than the calibration control were reported as negative.

$\mathrm{Bb} \mathrm{WB}$ testing for IgM and $\mathrm{IgG}$ reactivity was interpreted as positive if two bands from the following 6 antigens were reactive: $23,31,34,39,41$ and $93 \mathrm{kDa}$, with the following exceptions: for the IgG WB, if only the 31 and 41 or 31 and $93 \mathrm{kDa}$ bands were reactive the assay was interpreted as indeterminate; and for the $\operatorname{IgM~WB}$, if only the 41 and 93 $\mathrm{kDa}$ bands were reactive the assay was interpreted as negative. Positive and negative controls were run with all $\mathrm{Bb}$ WB tests.

RFB WB testing for IgM and IgG reactivity was performed using separate strips for the B. hermsii and B. turcica species. RFB WB testing for either IgM or IgG was interpreted as positive if two bands from the following four antigens were reactive on the strips from either species: 21-23, Glycerophosphodiester phosphodiesterase (GlpQ), 41 and 70-75kDa. Positive and negative controls were run with all RFB WB tests.

\section{Borrelia PCR testing}

Clinical samples were tested by multiplex PCR for the detection of $\mathrm{Bb}$, as described previously. ${ }^{18}$ PCR testing for RFB was performed using quantitative PCR (qPCR) targeting a 16S rDNA fragment. The Borrelia derivation of all positive $\mathrm{Bb}$ and RFB amplicons was confirmed by Sanger sequencing.

\section{B. henselae PCR testing}

Clinical samples were tested by PCR amplification of a Bartonella-specific DNA target. The PCR primers were targeted to a $320 \mathrm{bp}$ fragment at the $5^{\prime}$ end of $16 \mathrm{~S}$ rDNA. The Bartonella derivation of these $320 \mathrm{bp}$ amplicons was confirmed by Sanger sequencing.

\section{B. henselae fluorescent in situ hybridization (FISH) testing}

Formalin-fixed paraffin embedded skin tissue samples were deparaffinized as described previously. ${ }^{19}$ After the final wash with phosphate-buffered saline, the slides were dried and the skin sections were hybridized with a Bartonella-specific probe targeted to the 5' end of a Bartonella 16S rDNA fragment. The sections were labeled with Alexa 488 fluorescein isothiocyanate (FITC) dye in chaotropic buffer at $37^{\circ} \mathrm{C}$ for 30 minutes, followed by three 2-minute washes in wash buffer (saline-sodium citrate containing SDS) at ambient temperature. The sections were then counterstained with Sudan Black (Sigma-Aldrich Co., St Louis, MO, USA) for 20 minutes and dried in complete darkness. A drop of mounting medium was then added, and the sections were covered with a glass coverslip. Sections were read at 1,000× magnification using a light-emitting diode (LED) light source with custom filter sets (Fraen Corp, Cusago, Italy) for viewing green (excitation $490 \mathrm{~nm}$; emission 529-530 nm band-pass filter) in an Olympus BX laboratory light microscope.

\section{Results \\ Demographics}

The patient cohort consisted of 3 male and 27 female subjects ranging in the age from 37 to 87 years with a mean age \pm SD of 58.1 \pm 12.4 years. Patients resided in 10 US states (Texas, Virginia, California, Pennsylvania, Wisconsin, Indiana, Tennessee, Missouri, Washington and Colorado) and in three Canadian provinces (Alberta, Quebec and Ontario). The majority of patients resided in the province of Alberta (12) and the state of Texas (7). The geographic distribution and test results of patients are shown in Figure 1, and demographic data are listed in Table 1.

\section{BorreliaWB testing}

Serum samples from all 30 patients with MD were tested for reactivity to $\mathrm{Bb}$ and $\mathrm{RFB}$ antigens by $\mathrm{WB}$. Of the sera tested for each subject, 19/30 (63.3\%) were interpreted as positive for either $\mathrm{Bb}$ and/or RFB. Of these, 4/30 (13.3\%) reacted to $\mathrm{Bb}$ antigens alone, 11/30 (36.7\%) reacted to RFB antigens alone, and dual reactivity with both $\mathrm{Bb}$ and $\mathrm{RFB}$ was detected in $4 / 30(13.3 \%)$. Serum from $11 / 30$ patients $(36.7 \%)$ failed to react to antigens of either $\mathrm{Bb}$ or RFB group. Borrelia WB testing results are summarized in Table 2.

\section{Borrelia PCR testing}

Blood specimens from all 30 patients and skin specimens from 10 patients with MD were submitted for DNA amplification 


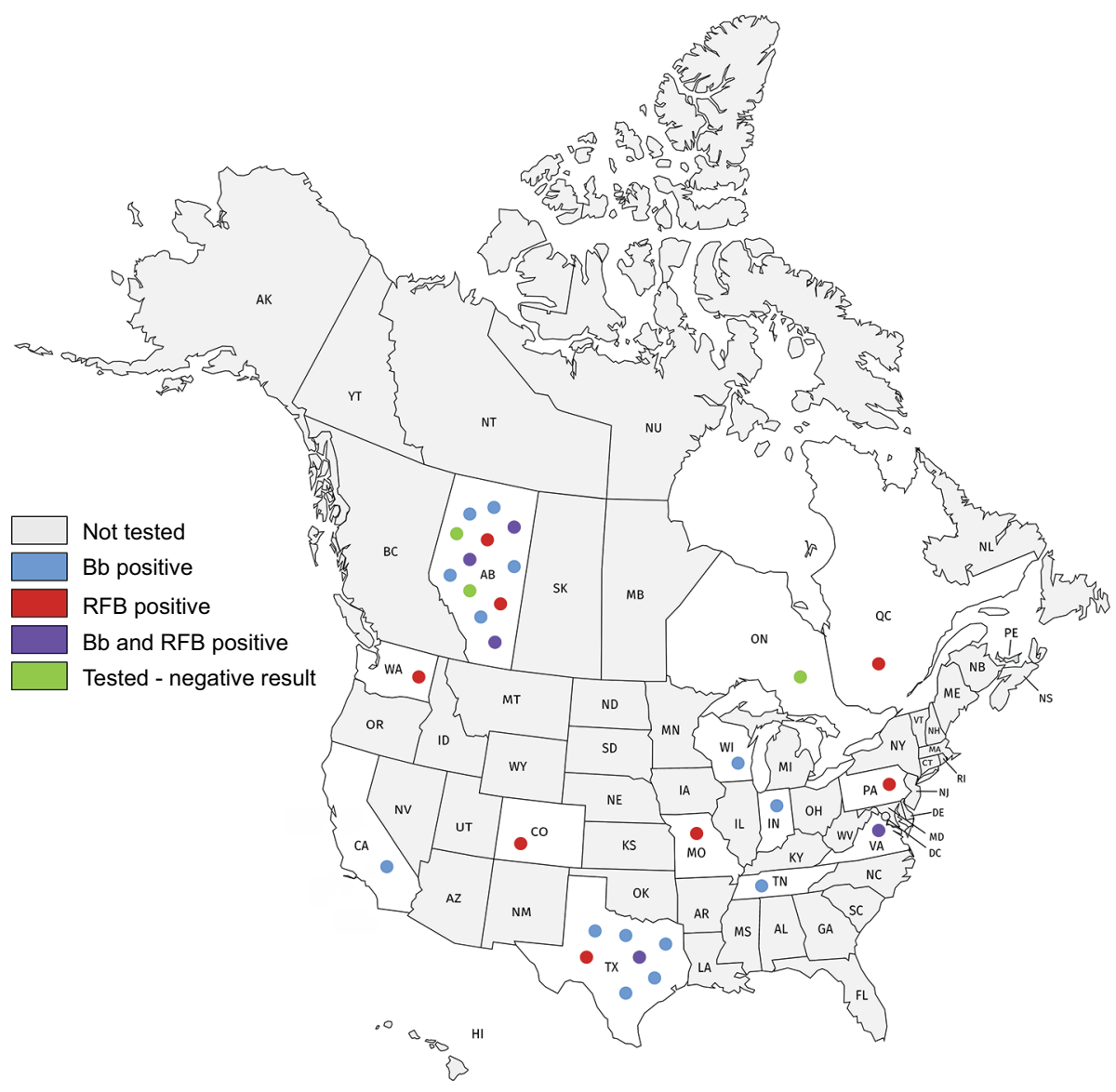

Figure I Geographic distribution of the MD patient cohort.

Abbreviations: Bb, Borrelia burgdorferi; MD, Morgellons disease; RFB, relapsing fever Borrelia.

using PCR technology. Amplicons to Bb DNA targets were obtained for specimens from 16/30 patients (53.3\%). Amplicons to RFB DNA targets were obtained for specimens from $9 / 30$ patients $(30 \%)$. Of those patients from whom amplicons were obtained, 7/30 (23.3\%) were positive for Bb amplicons but not RFB amplicons, 8/30 (26.7\%) were positive for RFB amplicons but not $\mathrm{Bb}$ amplicons, 1/30 (3.3\%) was positive for both $\mathrm{Bb}$ and RFB amplicons, and 14/30 (46.7\%) subjects were negative. Borrelia PCR results are summarized in Table 3.

\section{Combined Borrelia WB and PCR testing}

All 30 patients with MD were tested for $\mathrm{Bb}$ and/or RFB infection by both WB and PCR amplification of target DNA. Of the subjects tested, 27/30 (90\%) had a positive test result (either WB or PCR) for either $\mathrm{Bb}$ and/or RFB infection. Of these, $7 / 30$ (23.3\%) tested positive for $\mathrm{Bb}$ alone; 15/30 (50\%) tested positive for RFB alone and 5/30 (16.7\%) tested positive for both $\mathrm{Bb}$ and RFB. Only 3/30 (10\%) tested negative for both spirochete species. Of the three patients whose tests were negative, two were taking antibiotics at the time of sampling. In the MD cohort, 4/30 (13.3\%) tested positive for $\mathrm{Bb}$ alone by both $\mathrm{WB}$ seroreactivity and PCR detection of $\mathrm{Bb} \mathrm{DNA}, 4 / 30$ (13.3\%) tested positive for RFB alone by both WB seroreactivity and PCR detection of RFB DNA, and $0 / 30(0 \%)$ tested positive for both $\mathrm{Bb}$ and RFB by WB seroreactivity to $\mathrm{Bb}$ and $\mathrm{RFB}$ antigens and PCR detection of $\mathrm{Bb}$ and RFB DNA. Combined testing of $\mathrm{Bb}$ and RFB by $\mathrm{WB}$ and PCR is summarized in Table 4.

\section{B. henselae PCR testing}

Blood specimens from all 30 patients and skin specimens from 10 patients with MD were submitted for PCR amplification of $B$. henselae PCR gene targets. Amplicons from blood and/or skin specimens were obtained for samples from $6 / 30(20 \%)$ of the patients. B. henselae PCR results are summarized in Table 5.

\section{B. henselae FISH testing}

Formalin-fixed skin sections from a subset of $10 \mathrm{MD}$ patients were stained with an FITC-labeled DNA probe 
Table I Demographic data for the MD patient cohort

\begin{tabular}{|c|c|c|c|}
\hline $\begin{array}{l}\text { Patient } \\
\text { ID no. }\end{array}$ & Age (years) & Sex & $\begin{array}{l}\text { State or } \\
\text { province }\end{array}$ \\
\hline $\mathrm{I}$ & 66 & Female & $\mathrm{TX}$ \\
\hline 2 & 65 & Female & $A B$ \\
\hline 3 & 87 & Female & $\mathrm{TX}$ \\
\hline 4 & 59 & Female & $A B$ \\
\hline 5 & 74 & Male & $A B$ \\
\hline 6 & 68 & Female & $\mathrm{TX}$ \\
\hline 7 & 52 & Female & $\mathrm{TX}$ \\
\hline 8 & 64 & Female & $\mathrm{TX}$ \\
\hline 9 & 67 & Female & IN \\
\hline 10 & 52 & Female & VA \\
\hline $\mathrm{II}$ & 52 & Female & $\mathrm{QC}$ \\
\hline 12 & 51 & Female & $\mathrm{WI}$ \\
\hline 13 & 63 & Female & $A B$ \\
\hline 14 & 59 & Female & $\mathrm{MO}$ \\
\hline 15 & 61 & Female & $A B$ \\
\hline 16 & 37 & Female & $\mathrm{TX}$ \\
\hline 17 & 38 & Female & $A B$ \\
\hline 18 & 74 & Female & CA \\
\hline 19 & 58 & Female & PA \\
\hline 20 & 57 & Female & $A B$ \\
\hline 21 & 60 & Female & $\mathrm{TN}$ \\
\hline 22 & 54 & Female & ON \\
\hline 23 & 44 & Female & $A B$ \\
\hline 24 & 38 & Female & $A B$ \\
\hline 25 & 74 & Male & $A B$ \\
\hline 26 & 48 & Female & $\mathrm{TX}$ \\
\hline 27 & 76 & Female & $A B$ \\
\hline 28 & 57 & Female & $A B$ \\
\hline 29 & 51 & Male & $\mathrm{CO}$ \\
\hline \multirow[t]{2}{*}{30} & 38 & Female & WA \\
\hline & $\begin{array}{l}\text { Mean age } \pm S D: \\
58.1 \pm I 2.4 \text { years }\end{array}$ & $\begin{array}{l}27 \text { females, } \\
3 \text { males }\end{array}$ & \\
\hline
\end{tabular}

Abbreviation: MD, Morgellons disease.

for the detection of $B$. henselae target DNA. In the skin sections from these subjects, $3 / 10(30 \%)$ demonstrated positive FISH tests. Of the three patients who tested positive by FISH, two were also positive by PCR amplification of target DNA. $B$. henselae FISH results are summarized in Table 5.

\section{Discussion}

Positive testing for Borrelia has consistently been detected in MD patients, and consequently a spirochetal etiology for this filamentous dermopathy has been proposed., ${ }^{3,4,11,12}$ Serological and/or molecular positivity for Bbss is most consistently detected in MD patients, but positive testing for the Bbsl species Borrelia garinii and the RFB species Borrelia miyamotoi and B. hermsii has also been found in patients with this dermopathy. ${ }^{3,4,11,12,15}$ Serological and/or molecular positivity for Borrelia species was detected in $90 \%$
Table 2 WB test results for $\mathrm{Bb}$ and RFB

\begin{tabular}{|c|c|c|c|}
\hline $\begin{array}{l}\text { Patient } \\
\text { ID no. }\end{array}$ & Bb WB & RFB WB & $\begin{array}{l}\text { Infection } \\
\text { detected }\end{array}$ \\
\hline 1 & $+\lg M$ & $+\lg M$ & $\mathrm{Bb} / \mathrm{RFB}$ \\
\hline 2 & - & $+\lg M$ & RFB \\
\hline 3 & - & IND IgM & IND \\
\hline 4 & $+\lg M / \lg G$ & - & $\mathrm{Bb}$ \\
\hline 5 & - & - & - \\
\hline 6 & - & $+\lg M$ & RFB \\
\hline 7 & - & - & - \\
\hline 8 & IND IgG & $+\lg M$ & RFB \\
\hline 9 & - & $+\lg M$ & RFB \\
\hline 10 & - & - & - \\
\hline 11 & - & - & - \\
\hline 12 & - & $+\lg M / \lg G$ & RFB \\
\hline 13 & - & $+\lg M$ & RFB \\
\hline 14 & $+\lg M$ & - & $\mathrm{Bb}$ \\
\hline 15 & $+\lg M / \lg G$ & $+\lg M / \lg G$ & $\mathrm{Bb} / \mathrm{RFB}$ \\
\hline 16 & IND IgM & $+\lg M$ & RFB \\
\hline 17 & $+\lg M \lg G$ & - & $\mathrm{Bb}$ \\
\hline 18 & $+\lg M$ & - & $\mathrm{Bb}$ \\
\hline 19 & - & $+\lg M / \lg G$ & RFB \\
\hline 20 & - & $+\lg M$ & RFB \\
\hline 21 & - & - & - \\
\hline 22 & - & - & - \\
\hline 23 & $+\lg M$ & $+\lg G$ & $\mathrm{Bb} / \mathrm{RFB}$ \\
\hline 24 & $+\lg M / \lg G$ IND & $+\lg M / \operatorname{lgg}$ & $\mathrm{Bb} / \mathrm{RFB}$ \\
\hline 25 & - & $+\lg M$ & RFB \\
\hline 26 & - & - & - \\
\hline 27 & - & - & - \\
\hline 28 & - & - & - \\
\hline 29 & - & - & - \\
\hline 30 & - & $+\lg M$ & RFB \\
\hline Total & $\begin{array}{l}8+ \\
2 \text { IND }\end{array}$ & $\begin{array}{l}\text { I5+ } \\
\text { I IND }\end{array}$ & $\begin{array}{l}4 \text { Bb only } \\
\text { I I RFB only } \\
4 \text { dual } \mathrm{Bb} / \mathrm{RFB}\end{array}$ \\
\hline
\end{tabular}

Abbreviations: $\mathrm{Bb}$, Borrelia burgdorferi; IND, indeterminate; RFB, relapsing fever Borrelia; WB, Western blot.

of the MD subjects in this study, supporting the association between Borrelia and MD. Although we did not find positive tests in all of our subjects, positive testing for $\mathrm{Bb}$ and RFB was present at a much higher rate than would be expected for the general population. ${ }^{20-22}$ Positive testing was more frequently detected for RFB than for $\mathrm{Bb}$, and a significant number of patients had dual positivity for both $\mathrm{Bb}$ and RFB. Thus, the evidence demonstrates that MD is associated with a spectrum of Borrelia organisms rather than $\mathrm{Bb}$ alone. This variation may complicate the clinical picture in MD patients.

LD is an important disease in the northern hemisphere and is the most common vector-borne illness in the USA, justifiably drawing considerable worldwide attention. ${ }^{20,21}$ Relapsing fever is a neglected disease, even though it is a notable infectious vector-borne disease found in five out of 
seven continents. ${ }^{22-24}$ Most RFB cases in the USA are caused by B. miyamotoi, B. hermsii, B. lonestari, B. parkeri, and B. turicatae, and occur predominantly in western states. ${ }^{25-28} \mathrm{Bb}$ is transmitted by hardbodied (ixodid) ticks, while RFB are

Table 3 PCR test results for $\mathrm{Bb}$ and RFB

\begin{tabular}{|c|c|c|c|}
\hline $\begin{array}{l}\text { Patient ID } \\
\text { no. }\end{array}$ & Bb PCR & RFB PCR & $\begin{array}{l}\text { Infection } \\
\text { detected }\end{array}$ \\
\hline I & - & - & - \\
\hline 2 & - & - & - \\
\hline 3 & - & + (Skin) & RFB \\
\hline 4 & - & - & - \\
\hline 5 & - & - & - \\
\hline 6 & - & + & RFB \\
\hline 7 & + & - & $\mathrm{Bb}$ \\
\hline 8 & - & - & - \\
\hline 9 & - & + & RFB \\
\hline 10 & + & + & $\mathrm{Bb} / \mathrm{RFB}$ \\
\hline 11 & + & - & $\mathrm{Bb}$ \\
\hline 12 & - & - & - \\
\hline 13 & - & $+($ Skin $)$ & RFB \\
\hline 14 & + & - & $\mathrm{Bb}$ \\
\hline 15 & - & + & RFB \\
\hline 16 & - & - & - \\
\hline 17 & + & - & $\mathrm{Bb}$ \\
\hline 18 & + & - & $\mathrm{Bb}$ \\
\hline 19 & - & - & - \\
\hline 20 & - & - & - \\
\hline 21 & + & - & $\mathrm{Bb}$ \\
\hline 22 & - & - & - \\
\hline 23 & + & - & $\mathrm{Bb}$ \\
\hline 24 & - & - & - \\
\hline 25 & - & - & - \\
\hline 26 & - & + (Skin) & RFB \\
\hline 27 & - & + (Skin) & RFB \\
\hline 28 & - & - & - \\
\hline 29 & - & + (Skin) & RFB \\
\hline 30 & - & - & - \\
\hline Total & $8+$ & $9+$ & $\begin{array}{l}\text { 7/30 Bb only } \\
8 / 30 \text { RFB only } \\
\text { I/30 dual } \mathrm{Bb} / \mathrm{RFB}\end{array}$ \\
\hline
\end{tabular}

Abbreviations: Bb, Borrelia burgdorferi; RFB, relapsing fever Borrelia. primarily vectored by softbodied (argasid) ticks, and B. recurrentis is transmitted by the human body louse. Although most tickborne RFB species are transmitted by argasid ticks, $B$. miyamotoi and B. lonestari are transmitted by ixodid ticks. ${ }^{29,30}$

Testing for Borrelia is primarily focused on LD. The commercial two-tier serological test for LD endorsed by the Centers for Disease Control and Prevention (CDC) is highly specific for Bbss because it is based on detection of a single Bbss laboratory strain, B31. ${ }^{16,31-34}$ False negatives are common and can be caused by factors such as patient seronegativity and genetic diversity among Borrelia strains. ${ }^{31-38}$ Thus commercial serological tests for LD fail to capture the genetic spectrum of Borrelia capable of causing infection..$^{31-38}$ Serological testing for RFB is not commonly performed and is currently only available through a limited number of laboratories using "home brew" tests. ${ }^{17,29}$ Testing for MD and "Lyme-like illness" should embrace the diversity of Borrelia, including both $\mathrm{Bb}$ and RFB. ${ }^{17,33,36,38} \mathrm{WB}$ band patterns for $\mathrm{Bb}$ and RFB are unique, and serological tests based on one group of antigens will not adequately detect the other ${ }^{17}$ Our study emphasizes the necessity of testing for both $\mathrm{Bb}$ and RFB, not only in the MD population but in all suspected cases of tickborne disease.

PCR technology detected $\mathrm{Bb}$ and RFB infections in $53.3 \%$ of this cohort of MD patients, including cases that were missed by WB serological testing. For LD testing, the $\mathrm{CDC}$ does not recommend direct detection methods such as PCR detection of DNA, antigen detection, or culture. ${ }^{3,4,39}$ Serological techniques alone would miss valuable diagnostic evidence of infection for a sizable proportion of MD cases, particularly if the testing is only based on Bbss strain B31. Direct detection methods could offer useful clinical insight in suspected cases that are seronegative for LD.

Our study has several limitations, as outlined below. The cohort was too small to determine if there is a geographical pattern of infection among MD subjects. There were

Table 4 WB and PCR test results for $B b$ and RFB

\begin{tabular}{|l|l|l|l|l|}
\hline Patients tested & WB & PCR & Combined WB and PCR & Either WB or PCR \\
\hline Total Bb positive & $8(26.7 \%)$ & $8(26.7 \%)$ & $4(13.3 \%)$ & $12(40 \%)$ \\
\hline Total Bb negative & $22(73.3 \%)$ & $22(73.3 \%)$ & $26(86.7 \%)$ & $18(60 \%)$ \\
\hline Total RFB positive & $15(50 \%)$ & $9(30 \%)$ & $4(13.3 \%)$ & $20(66.7 \%)$ \\
\hline Total RFB negative & $15(50 \%)$ & $21(70 \%)$ & $26(86.7 \%)$ & $10(33.3 \%)$ \\
\hline Isolated Bb positive (RFB negative) & $4(13.3 \%)$ & $7(23.3 \%)$ & $4(13.3 \%)$ & $7(23.3 \%)$ \\
\hline Isolated RFB positive (Bb negative) & $\mathrm{II}(36.7 \%)$ & $8(26.7 \%)$ & $4(13.3 \%)$ & $15(50 \%)$ \\
\hline Bb/RFB dual positive & $4(13.3 \%)$ & $\mathrm{I}(3.3 \%)$ & $0(0 \%)$ & $5(16.7)$ \\
\hline Bb/RFB dual negative & $\mathrm{II}(36.7 \%)$ & $14(46.7 \%)$ & $22(73.3 \%)$ & $3(10 \%)$ \\
\hline Either Bb or RFB positive & $19(63.3 \%)$ & $16(53.3 \%)$ & $8(26.7 \%)$ & $27(90 \%)$ \\
\hline
\end{tabular}

Abbreviations: Bb, Borrelia burgdorferi; RFB, relapsing fever Borrelia; WB, Western blot. 
Table 5 B. henselae PCR and FISH test results

\begin{tabular}{|c|c|c|c|}
\hline Patient ID no. & PCR blood & PCR skin & FISH skin \\
\hline $\mathrm{I}$ & - & ND & ND \\
\hline 2 & - & ND & ND \\
\hline 3 & - & + & - \\
\hline 4 & - & ND & ND \\
\hline 5 & - & ND & ND \\
\hline 6 & + & - & - \\
\hline 7 & - & + & + \\
\hline 8 & - & - & - \\
\hline 9 & - & ND & ND \\
\hline 10 & - & ND & ND \\
\hline 11 & - & - & - \\
\hline 12 & - & ND & ND \\
\hline 13 & - & - & - \\
\hline 14 & - & ND & ND \\
\hline 15 & - & - & - \\
\hline 16 & - & ND & ND \\
\hline 17 & - & ND & ND \\
\hline 18 & - & ND & ND \\
\hline 19 & - & ND & ND \\
\hline 20 & - & ND & ND \\
\hline 21 & - & ND & ND \\
\hline 22 & - & ND & ND \\
\hline 23 & - & ND & ND \\
\hline 24 & - & ND & ND \\
\hline 25 & - & ND & ND \\
\hline 26 & - & + & + \\
\hline 27 & - & + & - \\
\hline 28 & - & ND & ND \\
\hline 29 & - & + & + \\
\hline 30 & - & ND & ND \\
\hline Total & I+ blood & $5+P C R$ & $3+\mathrm{FISH}$ \\
\hline
\end{tabular}

Abbreviations: B. henselae, Bartonella henselae; FISH, fluorescent in situ hybridization; ND, not done.

significant participant numbers only from the province of Alberta and the state of Texas (Figure 1 and Table 1). Our study selection was skewed to these two geographical areas because the Charles E. Holman Morgellons Disease Foundation is based in Texas and one of the authors of this study resides in Alberta. Thus referring doctors and volunteering participants had greater awareness of MD in these locations. While the numbers are not statistically significant because of the small cohort size and weighted recruitment, $\mathrm{Bb}$ was more frequently detected in Alberta subjects (5/10, 50\%) than in Texas subjects $(2 / 7,28 \%)$. Further studies with larger numbers of patients using broader recruitment methodologies are needed to better understand the distribution pattern of different spirochetal infections.

Of the three subjects who tested negatively, two were taking antibiotics during the time of specimen collection. This may have influenced the test results for these two individu- als, but no test for Borrelia is $100 \%$ sensitive ${ }^{16}$ It is possible that the negative subjects were infected with Borrelia strains that were not captured by the techniques employed in this study. However, it is also possible that spirochetes other than Borrelia such as Treponema and Leptospira may elicit this dermatological condition, and there is published evidence supporting this hypothesis. Dual infection with the human periodontal spirochete Treponema denticola and $\mathrm{Bb}$ has been reported in MD subjects. ${ }^{3,4}$ Spirochetal infection with a variety of treponemal species causes a filamentous skin disorder in cattle, bovine digital dermatitis, that resembles MD. ${ }^{2}$ In 1935 and 1938, cases of delusional parasitosis bearing symptomatic similarities to MD were published by the French physician Vié and the Swedish physician Ekbom who reported, respectively, that $6 / 8$ and $3 / 7$ of their case subjects had syphilis. ${ }^{4}$ Thus it is possible that in these cases the etiology of MD symptoms was a pathogen other than Borrelia.

Other pathogens have been detected in MD tissue and body fluid specimens, some of which can be tickborne (Bartonella and Rickettsia spp.) and others that are commonly encountered in humans (Treponema denticola and Helicobacter pylori). ${ }^{3,4,14,40-43}$ We detected $B$. henselae co-infection in our MD cohort using PCR (20\% of blood and/or skin samples positive) and FISH ( $30 \%$ of skin samples positive). Thus positive testing for this pathogen appears to occur in a subgroup of MD patients, confirming the findings of previous studies. ${ }^{1,13}$ Co-infecting vector-borne pathogens such as $B$. henselae could be co-involved primary etiological factors in some MD patients or they may be secondary or exacerbating factors. Likewise, T. denticola and H. pylori could be primary or secondary etiological factors in MD evolution. As in previous studies, ${ }^{1,2,5,13}$ our cohort was comprised of primarily middle-aged Caucasian women. Etiological factors in MD such as pathogen variation, genetic background, hormonal influences, and immune status remain to be fully elucidated. ${ }^{3,4}$

\section{Conclusion}

MD is associated with positive testing for spirochetal pathogens. Both $\mathrm{Bb}$ and RFB are encountered in the MD patient population and appear to be important primary etiological factors. MD may also be associated with tick-borne coinfections that could play a role in the evolution of dermopathy. The fact that RFB infection appears equal to $\mathrm{Bb}$ in terms of frequency highlights the complexity of Borrelia infection in this patient population and the need for better testing that reflects spirochetal genetic diversity. The role of Borrelia and coinfecting pathogens in the development of MD warrants further investigation. 


\section{Acknowledgments}

The authors thank Dave Franklin, Diana Canchola and Jeannie Ramos for technical assistance. This study was supported by a grant from the Lindorf Family Foundation, Newark, OH, USA.

\section{Author contributions}

All the authors contributed toward data analysis, drafting and revising the paper, gave final approval of the version to be published and agreed to be accountable for all aspects of the work.

\section{Disclosure}

JSS is president and laboratory director of IGeneX Clinical Laboratory, Palo Alto, CA, USA. RBS is the owner of Union Square Medical Associates, a medical practice that treats tick-borne diseases in San Francisco, CA, USA. The other authors report no conflicts of interest in this work.

\section{References}

1. Savely VR, Stricker RB. Morgellons disease: Analysis of a population with clinically confirmed microscopic subcutaneous fibers of unknown etiology. Clin Cosmet Investig Dermatol. 2010;3:67-78.

2. Middelveen MJ, Stricker RB. Filament formation associated with spirochetal infection: a comparative approach to Morgellons disease. Clin Cosmet Investig Dermatol. 2011;4:167-177.

3. Middelveen MJ, Stricker RB. Morgellons disease: a filamentous borrelial dermatitis. Int J Gen Med. 2016;9(9):349-354.

4. Middelveen MJ, Fesler MC, Stricker RB. History of Morgellons disease: from delusion to definition. Clin Cosmet Investig Dermatol. 2018;11:71-90.

5. Pearson ML, Selby JV, Katz KA, et al. Unexplained Dermopathy Study Team. Clinical, epidemiologic, histopathologic and molecular features of an unexplained dermopathy. PLoS One. 2012;7(1):e29908.

6. Shah R, Taylor RE, Bewley A. Exploring the psychological profile of patients with delusional infestation. Acta Derm Venereol. 2017;97(1):98-101.

7. J. Middelveen M, Rasmussen EH, Kahn DG, Stricker RB. Morgellons disease: a chemical and light microscopic study. J Clin Exp Dermatol Res. 2012;03(01):140.

8. Middelveen MJ, Mayne PJ, Kahn DG, Stricker RB. Characterization and evolution of dermal filaments from patients with Morgellons disease. Clin Cosmet Investig Dermatol. 2013;6:1-21.

9. Savely VR, Leitao MM, Stricker RB. The mystery of Morgellons disease: infection or delusion? Am J Clin Dermatol. 2006;7(1):1-5.

10. Savely VR, Stricker RB. Morgellons disease: the mystery unfolds. Expert Rev Dermatol. 2007;2(5):585-591.

11. Middelveen MJ, Burugu D, Poruri A, et al. Association of spirochetal infection with Morgellons disease. F1000Res. 2013;2:25.

12. Middelveen MJ, Bandoski C, Burke J, et al. Exploring the association between Morgellons disease and Lyme disease: identification of Borrelia burgdorferi in Morgellons disease patients. BMC Dermatol. 2015;15(1):1.

13. Fesler MC, Middelveen MJ, Stricker RB. Clinical evaluation of Morgellons disease in a cohort of North American patients. Dermatol Reports. 2018;10(1):7660.

14. Mayne PJ. Clinical determinants of Lyme borreliosis, babesiosis, bartonellosis, anaplasmosis, and ehrlichiosis in an Australian cohort. Int J Gen Med. 2015;8:15-26.

15. Mayne P, English JS, Kilbane EJ, Burke JM, Middelveen MJ, Stricker RB. Morgellons: a novel dermatological perspective as the multisystem infective disease borreliosis. F1000Res. 2013;2:118.
16. Shah JS, Cruz D I, Narciso W, Lo W, Harris NS. Improved sensitivity of Lyme disease Western blots prepared with a mixture of Borrelia burgdorferi strains 297 and B31. Chronic Dis Int. 2014;1(2):7.

17. Middelveen MJ, Shah JS, Fesler MC, Stricker RB. Relapsing fever Borrelia in California: A pilot serological study. Int J Gen Med. 2018; 11:373-382.

18. Shah JS, D'Cruz I, Ward S, Harris NS, Ramasamy R. Development of a sensitive PCR-dot blot assay to supplement serological tests for diagnosing Lyme disease. Eur J Clin Microbiol Infect Dis. 2018;37(4):701-709.

19. Sapi E, Balasubramanian K, Poruri A, et al. Evidence of in vivo existence of Borrelia biofilm in borrelial lymphocytomas. Eur J Microbiol Immunol. 2016;6(1):9-24.

20. CDC 2016. Lyme disease data tables. Available from: https://www.cdc. gov/lyme/stats/tables.html. Accessed September 27, 2018.

21. Bush LM, Vazquez-Pertejo MT. Tick borne illness-Lyme disease. Dis Mon. 2018;64(5):195-212.

22. CDC 2016. Tick-borne relapsing fever (TBRF). Information for clinicians. Available from: https://www.cdc.gov/relapsing-fever/clinicians/ index.html. Accessed August 18, 2018.

23. Lopez JE, Krishnavahjala A, Garcia MN, Bermudez S. Tick-borne relapsing fever spirochetes in the Americas. Vet Sci. 2016;3(3):16.

24. Talagrand-Reboul E, Byer PH, Bergström S, Vial L, Boulanger N. Relapsing fevers: Neglected tick-borne diseases. Front Cell Infect Microbiol. 2018;4(8)98

25. Burkot TR, Mullen GR, Anderson R, Schneider BS, Happ CM, Zeidner NS. Borrelia lonestari DNA in adult Amblyomma americanum ticks, Alabama. Emerg Infect Dis. 2001;7:471-743.

26. Bunikis J, Tsao J, Garpmo U, Berglund J, Fish D, Barbour AG. Typing of Borrelia relapsing fever group strains. Emerg Infect Dis. 2004;10:1661-1664.

27. Schwan TG, Raffel SJ, Schrumpf ME, S, et al. Tick-borne relapsing fever and Borrelia hermsii, Los Angeles County, California, USA. Emerg Infect Dis. 2009;15:1026-1031.

28. Vuyyuru R, Liu H, Manser T, Alugupalli KR. Characteristics of Borrelia hermsii infection in human hematopoietic stem cell-engrafted mice mirror those of human relapsing fever. Proc Natl Acad Sci USA. 2011;108:20707-20712.

29. Wagemakers A, Staarink PJ, Sprong H, Hovius JWR. Borrelia miyamotoi: a widespread tick-borne relapsing fever spirochete. Trends Parasitol. 2015;31:260-269.

30. Cutler SJ, Ruzic-Sabljic E, Potkonjak A, Emerging borreliae - Expanding beyond Lyme borreliosis. Mol Cell Probes. 2017;31:22-27.

31. Stricker RB, Johnson L. Serologic tests for Lyme disease: more smoke and mirrors. Clin Infect Dis. 200815;47(8):1111-1112.

32. Cook MJ, Puri BK. Commercial test kits for detection of Lyme borreliosis: a meta-analysis of test accuracy. Int J Gen Med. 2016;9:427-440.

33. Ogden NH, Margos G, Aanensen DM, et al. Investigation of genotypes of Borrelia burgdorferi in Ixodes scapularis ticks collected during surveillance in Canada. Appl Environ Microbiol. 2011;77(10): 3244-3254.

34. Sperling J, Middelveen M, Klein D, Sperling F. Evolving perspectives on lyme borreliosis in Canada. Open Neurol J. 2012;6:94-103.

35. Dattwyler RJ, Volkman DJ, Luft BJ, Halperin JJ, Thomas J, Golightly MG. Seronegative Lyme disease. N Engl J Med. 1988;319(22):1441-1446.

36. Péter O, Bretz AG, Bee D. Occurrence of different genospecies of Borrelia burgdorferi sensu lato in Ixodid ticks of Valais, Switzerland. Eur J Epidemiol. 1995;11(4):463-467.

37. Sertour N, Cotté V, Garnier M, Malandrin L, Ferquel E, Choumet V. Infection kinetics and tropism of Borrelia burgdorferi sensu lato in mouse after natural (via ticks) or artificial (needle) infection depends on the bacterial strain. Front. Microbiol. 2018;9:1722.

38. Girard YA, Federova N, Lane RS. Genetic diversity of Borrelia burgdorferi and detection of B. bissettii-like DNA in serum of north-coastal California residents. J Clin Microbiol. 2011;49(3):945-954.

39. CDC 2015. Lyme disease. Laboratory tests that are not recommended. Available from: https://www.cdc.gov/lyme/diagnosistesting/labtest/ otherlab/index.html. Accessed August 18, 2018. 
40. Allen L, Saylor-Hefley C. Morgellons under investigation: identification of associated microorganisms by molecular analysis of epithelial samples. Presented at: 7thAnnual Medical-Scientific Conference on Morgellons Disease; March 29-30, 2014; Austin, TX. Available from: http://www.thecehf.org/ resources/OSU\%20_2015\%20_Research.pdf. Accessed August 18, 2018.

41. Bandoski $\mathrm{C}$ [home page on the Internet]. Evidence for the presence of human pathogens Borrelia and Helicobacter in Morgellons patients' skin samples. Presented at: 7th Annual Medical-Scientific Conference on Morgellons Disease; March 29-30, 2014; Austin, TX. Available from: http://www.thecehf.org/cheryl-bandoski.html. Accessed August 18, 2018.
42. Shah J.S. [homepage on the Internet]. Morgellons disease - chronic form of Borrelia infection? Presented at: 9th Annual Medical-Scientific Conference on Morgellons Disease; April 30-May 1, 2016; Austin, TX. Available from: http://www.thecehf.org/jyotsna-s-shah,-phd.html. Accessed August 18, 2018.

43. Lewis J, Lloyd V.K, Robichaud G.A. [homepage on the Internet]. Evidence of bacterial co-infections in Morgellons and Lyme patients. Presented at: 11th Annual Medical-Scientific Conference on Morgellons Disease; April 14-15, 2017; Austin, TX. Available from: http://www. thecehf.org/julie-lewis.html. Accessed August 18, 2018.

\section{Publish your work in this journal}

Clinical, Cosmetic and Investigational Dermatology is an international, peer-reviewed, open access, online journal that focuses on the latest clinical and experimental research in all aspects of skin disease and cosmetic interventions. This journal is included on PubMed. The manuscript management system is completely online and includes a very quick and fair peer-review system, which is all easy to use. Visit http://www.dovepress.com/testimonials.php to read real quotes from published authors 